\title{
Climate change, parasitism and the structure of intertidal ecosystems
}

\author{
R. Poulin ${ }^{1 *}$ and K.N. Mouritsen ${ }^{2}$ \\ ${ }^{1}$ Department of Zoology, University of Otago, PO Box 56, Dunedin, \\ New Zealand: ${ }^{2}$ Department of Marine Ecology, Institute of Biological \\ Sciences, University of Aarhus, Finlandsgade 14, DK-8200 Aarhus N, \\ Denmark
}

\begin{abstract}
Evidence is accumulating rapidly showing that temperature and other climatic variables are driving many ecological processes. At the same time, recent research has highlighted the role of parasitism in the dynamics of animal populations and the structure of animal communities. Here, the likely interactions between climate change and parasitism are discussed in the context of intertidal ecosystems. Firstly, using the soft-sediment intertidal communities of Otago Harbour, New Zealand, as a case study, parasites are shown to be ubiquitous components of intertidal communities, found in practically all major animal species in the system. With the help of specific examples from Otago Harbour, it is demonstrated that parasites can regulate host population density, influence the diversity of the entire benthic community, and affect the structure of the intertidal food web. Secondly, we document the extreme sensitivity of cercarial production in parasitic trematodes to increases in temperature, and discuss how global warming could lead to enhanced trematode infections. Thirdly, the results of a simulation model are used to argue that parasitemediated local extinctions of intertidal animals are a likely outcome of global warming. Specifically, the model predicts that following a temperature increase of less than $4^{\circ} \mathrm{C}$, populations of the amphipod Corophium volutator, a hugely abundant tube-building amphipod on the mudflats of the Danish Wadden Sea, are likely to crash repeatedly due to mortality induced by microphallid trematodes. The available evidence indicates that climate-mediated changes in local parasite abundance will have significant repercussions for intertidal ecosystems. On the bright side, the marked effects of even slight increases in temperature on cercarial production in trematodes could form the basis for monitoring programmes, with these sensitive parasites providing early warning signals of the environmental impacts of global warming.
\end{abstract}

\section{Introduction}

Climate change and global warming scenarios, once viewed as the wild prophecies of a small band of environmental scientists, are now accepted as facts by the broader scientific community and by society at large. The predictions for the next few decades include changes in

*Fax: + 64-3-479-7584

E-mail: robert.poulin@stonebow.otago.ac.nz air and sea surface temperatures, coupled with changes in precipitation, sea level, and ocean salinity and circulation patterns. There is no doubt that these environmental changes will impact natural ecosystems in one way or another. Weather and climate affect several ecological processes, from the performance of individual organisms, to the dynamics of populations and the distribution of species. This has been clearly illustrated by a series of recent studies that have linked changes in ecosystem properties and functions with large-scale climate fluctuations (Holmgren et al., 2001; Mysterud et al., 2001; 
Ottersen et al., 2001; Walther et al., 2002; Stenseth et al., 2002,2003 ). In particular, temperature is emerging as a key driving force behind many ecological processes.

Although often not emphasized as much as other ecological interactions, the extent and intensity of parasitism can also be modulated by climatic conditions (Mouritsen \& Poulin, 2002a). Parasites can regulate the abundance of their host population (e.g. Scott, 1987; Hudson et al., 1998; Albon et al., 2002), influence the composition and structure of animal communities (Minchella \& Scott, 1991; Combes, 1996; Mouritsen \& Poulin, 2002b), and affect the functioning of ecosystems (Thomas et al., 2005). Any influence of climate on parasitism is therefore potentially important for natural communities and ecosystems. Recent reports have highlighted the causal relationship between climate change and emerging parasitic diseases, i.e. diseases suddenly increasing in either local prevalence or geographical distribution (e.g. Harvell et al., 1999, 2002; Patz et al., 2000; Marcogliese, 2001; Lafferty et al., 2004). There is also evidence that climate can act to synchronize cycles of host population abundance by directly affecting the survival and transmission of parasite infective stages (Cattadori et al., 2005). Thus, the many direct and indirect effects of temperature and other climatic variables on parasite transmission are bound to have community-wide impacts.

Here, the potential impact of climate-mediated increases in parasitism on the structure and biodiversity of intertidal ecosystems is discussed. The discussion applies more broadly to other ecosystems; we only focus on the intertidal zone as a model system. Located at the interface between land and sea, the intertidal zone is the best-studied marine ecosystem, and also the habitat most likely to be affected by both atmospheric and oceanic changes. Specifically, three general questions are addressed: (i) Do parasites play important ecological roles in intertidal communities? (ii) How is climate change likely to affect the local abundance of parasites in intertidal systems? (iii) Can we predict how climate-mediated increases in parasitism may impact on intertidal populations and/or communities?

\section{Roles of parasites in intertidal systems}

Earlier reviews have argued that parasites play major roles in intertidal ecosystems (Lauckner, 1987; Sousa, 1991; Mouritsen \& Poulin, 2002b). Here, the importance of parasites is illustrated using the soft-sediment intertidal communities of Otago Harbour (South Island, New Zealand) as a case study. Otago Harbour is approximately $20 \mathrm{~km}$ long and about $2-3 \mathrm{~km}$ wide on average, and it consists of several sheltered bays that have been the subject of numerous ecological and parasitological studies over the past several years. For parasites to be important determinants of community structure, they must be relatively abundant, and their impact must extend to a level beyond that of the individual host, i.e. to the population or community. These two issues are addressed in turn.

First, are parasites common among the invertebrates on the Otago Harbour mudflats? For macroparasites the answer is yes, with trematodes being particularly abundant. Trematodes use a mollusc, usually a gastropod, as first intermediate host in their complex life cycle; cercariae produced in the first intermediate host generally go on to encyst in a second intermediate host, before the cycle is completed via trophic transmission to a vertebrate definitive host. Table 1 lists all the mollusc species from Otago Harbour soft-sediment flats that have an adult shell length greater than $5 \mathrm{~mm}$. Without exception, each mollusc species serves as first intermediate host to at least one trematode species. This is not surprising, as trematodes are known to infect most major gastropod taxa around the world (see Pechenik et al., 2001). In most cases, the prevalence of infection is rather low, with fewer than $10 \%$ of individuals in a population infected by trematodes (table 1). This is typical of the values found in other surveys from around the globe (Poulin \& Mouritsen, 2003). However, in many populations of the mudsnail Zeacumantus subcarinatus, an abundant grazer of microalgae throughout Otago Harbour, more than half of the population is infected by the microphallid

Table 1. Molluscs of Otago Harbour intertidal mudflats, and the trematodes that use them as first intermediate hosts.

\begin{tabular}{llcl}
\hline Mollusc species & \multicolumn{1}{c}{ Trematodes } & Prevalence* $(\%)$ & \multicolumn{1}{c}{ Reference } \\
\hline Snails & & & \\
Zeacumantus subcarinatus & Maritrema novaezealandensis & $5-70$ & Fredensborg et al., 2005 \\
& Microphallus sp. & $1-2$ & Fredensborg et al., 2005 \\
& Acanthoparyphium sp. & $5-10$ & Fredensborg et al., 2005 \\
& Philophthalmid sp. & $5-10$ & Fredensborg et al., 2005 \\
& Heterophyid sp & $2-3$ & Fredensborg et al., 2005 \\
Cominella glandiformis & Curtuteria australis & $3-6$ & Unpublished data \\
Diloma subrostrata & Trematode sp. & $1-2$ & Unpublished data \\
Melagraphia aethiops & Opecoelid sp. & $10-15$ & Donald et al., 2004 \\
Amphibola crenata & Opecoelid sp. & $2-3$ & Donald et al., 2004 \\
Bivalves & Trematode sp. & $2-5$ & Unpublished data \\
Austrovenus stutchburyi & Trematode sp. & $2-4$ & Poulin et al., 2000 \\
Macomona liliana & Gymnophallid sp. & $?$ & $*$ ** \\
\hline
\end{tabular}

* Range of values from different sites within the Harbour.

** Not yet positively identified as first intermediate host, but appears to be the only potential candidate in Otago Harbour. Austrovenus stutchburyi acts as second intermediate host for this trematode (see table 2). 
trematode Maritrema novaezealandensis (table 1). Given that infection by the first larval stages (sporocysts and rediae) of trematodes almost invariably leads to host castration (Sousa, 1983; Pearson \& Cheng, 1985; Mouritsen \& Jensen, 1994; see review in Mouritsen \& Poulin, $2002 b)$, the consequences of high prevalence can be serious at the population level, as illustrated below.

Both large bivalves and all three intertidal crab species found in Otago Harbour are hosts to a diverse fauna of other parasites (table 2). The prevalences and intensities of acanthocephalans, nematodes and trematode metacercariae in these hosts are very high (table 2 ), such that it is very difficult to find an uninfected adult individual of these host species in Otago Harbour. Few other invertebrate species have been surveyed to date, but parasites are also common in these other species. For instance, metacercariae of the trematode Maritrema novaezealandensis occur in more than $50 \%$ of amphipods, Paracalliope novizealandiae (Fredensborg et al., 2004b). Metacercariae of M. novaezealandensis and other trematode species are also common in other, unidentified amphipod species from Otago Harbour (T. Leung, B. Fredensborg \& R. Poulin, unpublished data). The trematodes, acanthocephalans and nematodes found in invertebrates use vertebrates, mainly birds but also fish, as definitive hosts. Given their prevalence in invertebrates, these parasites must also be common in the vertebrate predators (e.g. Latham \& Poulin, 2002a; Fredensborg et al., 2004a). Therefore, parasites are ubiquitous components of the Otago Harbour intertidal community, occurring in hosts at all levels in the food chains.

The second question one must ask is whether parasites play important ecological roles. Being abundant is relevant only if they have measurable effects on host population and community parameters. Two examples from Otago Harbour are used to illustrate the importance of parasites. The first example involves the trematode Maritrema novaezealandensis and its snail first intermediate host, Zeacumantus subcarinatus.
The snail is characterized by direct development, i.e. it has no planktonic larvae. Recruitment of new individuals to local populations therefore depends on local reproduction rather than on immigration. The trematode $M$. novaezealandensis, and the few other, less common trematode species also exploiting the snail Z. subcarinatus, all castrate their gastropod host (Fredensborg et al., 2005). Within Otago Harbour, the combined prevalence of these trematodes ranges from about $5 \%$ in some localities to over $80 \%$ in others. The total reproductive output of some snail populations can thus be severely depressed by trematodes. As a consequence, across localities within the Harbour, local trematode prevalence correlates negatively with both snail population density and biomass (Fredensborg et al., 2005). Other local variables, such as food abundance for the snails, play only secondary roles in determining local snail abundance, indicating that trematode parasitism is a key factor regulating snail populations.

Our other example involves two echinostomatid trematodes, Curtuteria australis and Acanthoparyphium sp., and their second intermediate host, the cockle Austrovenus stutchburyi. Following their release from snail first intermediate hosts, cercariae of these two trematode species enter a cockle through its inhalant siphon, and then encyst as metacercariae in the cockle's foot (Babirat et al., 2004). As they accumulate, metacercariae replace muscle tissue, obstruct the flow of haemolymph into the foot, and eventually impair significantly the cockle's ability to re-burrow if dislodged to the sediment surface (Thomas \& Poulin, 1998; Mouritsen, 2002a). As a consequence of trematode infection, mudflats within Otago Harbour are littered with live cockles stranded at the surface, the local density of surface cockles being proportional to local trematode abundance. This seemingly minor effect on cockle hosts has several major repercussions on the entire intertidal community. The physical nature of the habitat will be drastically modified in at least three ways. Firstly, the reduced mobility of infected cockles will lead to reduced

Table 2. Molluscs and crabs of Otago Harbour intertidal mudflats, and their trematode (metacercariae, $\mathrm{T}$ ), nematode $(\mathrm{N})$, acanthocephalan (A) and copepod (C) parasites.

\begin{tabular}{|c|c|c|c|c|}
\hline Host species & Parasites & Prevalence* $(\%)$ & $\begin{array}{l}\text { Mean intensity* } \\
\text { (no. per host) }\end{array}$ & Reference \\
\hline \multicolumn{5}{|l|}{ Bivalves } \\
\hline \multirow{4}{*}{ Austrovenus stutchburyi } & Curtuteria australis, $\mathrm{T}$ & 100 & $50-200$ & Babirat et al., 2004 \\
\hline & Acanthoparyphium sp., $\mathrm{T}$ & 100 & $50-200$ & Babirat et al., 2004 \\
\hline & Gymnophallid sp., T & 90 & $50-80$ & Poulin et al., 2000 \\
\hline & Pseudomyicola spinosus, C & $5-10$ & $1-2$ & Poulin et al., 2000 \\
\hline Macomona liliana & Echinostomatid sp., $\mathrm{T}$ & $90-100$ & $10-30$ & Unpublished data \\
\hline \multicolumn{5}{|l|}{ Crabs } \\
\hline \multirow[t]{5}{*}{ Macrophthalmus hirtipes } & Maritrema novaezealandensis, $\mathrm{T}$ & $90-100$ & $20-100$ & Poulin et al., 2003 \\
\hline & Levinseniella sp., $\mathrm{T}$ & $80-90$ & $5-15$ & Poulin et al., 2003 \\
\hline & Profilicollis spp., A & $80-100$ & $5-15$ & Latham \& Poulin, 2002b \\
\hline & Ascarophis sp., N & $2-4$ & $1-2$ & Moravec et al., 2003 \\
\hline & Acuariid sp., $\mathrm{N}$ & 90 & $3-8$ & Moravec et al., 2003 \\
\hline \multirow[t]{2}{*}{ Hemigrapsus crenulatus } & Maritrema novaezealandensis, $\mathrm{T}$ & $80-90$ & $10-20$ & Poulin et al., 2003 \\
\hline & Profilicollis spp., A & $60-90$ & $2-6$ & Latham \& Poulin, 2002b \\
\hline Hemigrapsus edwardsii & Profilicollis spp., A & $85-100$ & $5-15$ & Latham \& Poulin, 2002b \\
\hline
\end{tabular}

\footnotetext{
* Typical value or range of values from different sites within the Harbour.
} 
bioturbation (i.e. reduced mixing) of the sediments. Secondly, the otherwise smooth mudflat surface will have greater heterogeneity, with surface-stranded cockles providing refuges and attachment substrate for other organisms. Thirdly, the presence of surface cockles modifies seabed hydrodynamics and leads to altered sedimentation patterns and a greater settling of fine particles (Mouritsen \& Poulin, 2005a). The response of the biotic community to these physical changes is significant in many ways. Experimental studies have shown that the density, the species richness and the diversity of major taxonomic and functional groups of benthic organisms are generally increased by the presence of surface cockles in an area (Thomas et al., 1998; Mouritsen \& Poulin, 2005a). In addition, the zonation patterns of animals that use cockles as either substrate or food, such as limpets, anemones or whelks, are also affected by the parasiteinduced surfacing of cockles (Mouritsen \& Poulin, 2005b). Thus, the direct impact of the two trematode species on their cockle hosts has cascading effects extending to the entire intertidal community.

Whereas the effect of selected parasite species can be important, the concerted action of the entire parasite fauna can also influence other aspects of the community or ecosystem. For instance, in the Otago Harbour food web, parasites act to increase food chain length and the general complexity of the food web (Thompson et al., 2005); the same influence of parasites is seen in other similar food webs (Huxham et al., 1995). These results suggest that parasites can affect energy flow through the food web, as well as contributing to the overall stability and resilience of the web.

In summary, parasites are both common and functionally important components of the Otago Harbour softsediment intertidal community. There is nothing unique about Otago Harbour; it is a typical intertidal ecosystem, and parasites very likely play similar roles elsewhere. The next question is whether, and how, parasites and their ecological importance are likely to be influenced by predicted changes in climate.

\section{Temperature and the local abundance of parasites}

Among the many predicted changes in climate that have emerged in the scientific literature, there is one almost universal theme: air and sea surface temperatures are expected to rise by a few degrees over the next several decades, on a global scale from the Arctic to the Antarctic (e.g. Vaughan et al., 2003; Phoenix \& Lee, 2004). The magnitude of the temperature increase will vary from one geographic region to the next, and some areas may incur no change at all, but these details do not detract from the fact that global temperatures are slowly rising. The potential impacts of global warming on parasitic diseases include an expansion of the geographical range of many parasites and the emergence of previously unimportant pathogens (Harvell et al., 1999, 2002; Marcogliese, 2001; Mouritsen \& Poulin, 2002a; Lafferty et al., 2004). On a local scale, higher temperatures can also directly impact the developmental rates and transmission success of parasites, promoting higher local abundance of certain parasites.
In intertidal ecosystems, as well as in other systems, trematodes are obvious candidates for temperaturemediated increases in local abundance. The production of cercariae in snail first intermediate hosts is a crucial step in the transmission cycles of trematodes. Depending on the species, a single miracidium larva infecting a snail can go on to produce between $10^{2}$ to $10^{6}$ cercariae over the course of days, months or years. Several experimental studies have shown that within the range of temperatures in which host and parasite can live, an increase in temperature is almost invariably coupled with an increase in cercarial output (e.g. Lo \& Lee, 1996; Umadevi \& Madhavi, 1997; Mouritsen, 2002b; Fredensborg et al., 2005). Higher temperatures not only trigger the release of cercariae from snails, but they also accelerate the production of cercariae within snails. Thus, global warming could cause an increase in the spring and early summer release of cercarial infective stages in intertidal areas. Obviously, higher temperatures will also impact the other ectothermic animals living in the intertidal zone, in ways that may nullify the greater proliferation of trematodes. For instance, for the temperature-mediated increase in cercarial output to have an ecological impact, it would have to be greater than what the temperature-mediated increase in host metabolism and immunity can cope with. In ectothermic animals, the rate of most physiological processes typically increases by a factor of 2 or 3 per $10^{\circ} \mathrm{C}$ increase in temperature (Schmidt-Nielsen, 1997; Willmer et al., 2000). How does the increase in the rate of cercarial output compare with these figures? A survey of published studies indicates that cercarial production responds to temperature increases much more markedly than other physiological processes (fig. 1). Indeed, many studies report 10-fold, even 100-fold (see fig. 1), increases in

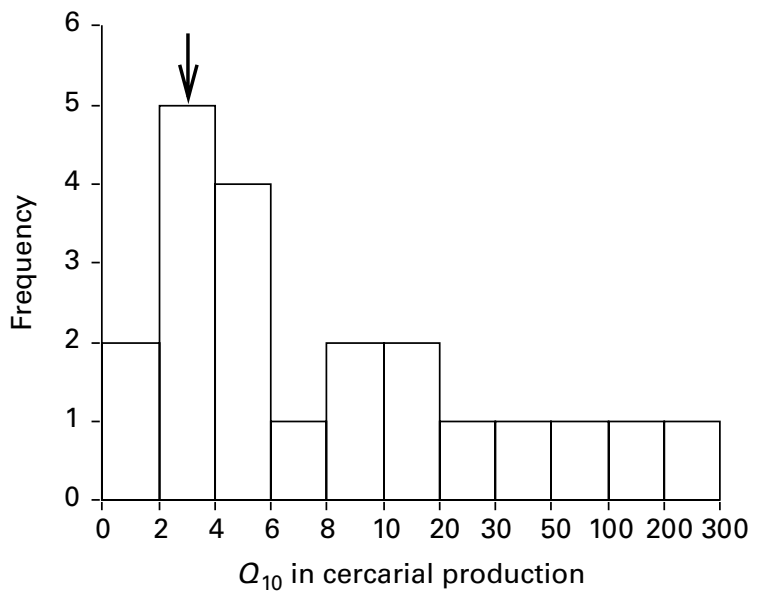

Fig. 1. Frequency distribution of $Q_{10}$ values for cercarial production in 21 species of trematodes. The $Q_{10}$ quantifies the relative rate of increase in cercarial output associated with a $10^{\circ} \mathrm{C}$ increase in temperature: a value of 1 indicates no change, a value of 2 indicates a doubling, a value of 3 indicates a tripling, etc. The scale on the $x$-axis is contracted toward the right-hand side of the figure. The arrow indicates the typical $Q_{10}$ values generally recorded for physiological and metabolic processes (from Poulin, 2006). 
cercarial output when temperature rises by $10^{\circ} \mathrm{C}$, well above the 2- or 3-fold values usually associated with physiological processes (Poulin, 2006). These findings suggest that global warming will be accompanied by mass proliferation of trematode infective stages.

But will this result in higher infection levels in the next hosts of trematodes? Two caveats need to be addressed. Firstly, although a rise in temperature will trigger an increase in cercarial output, this may be short-lived. At higher temperatures, and with cercarial production greatly enhanced, the snail host may not live as long as it would normally. However, this may not matter. A shortlived peak in cercarial release may be sufficient to cause extensive mortality in the next host of the trematode. Laboratory studies have shown that the exposure of second intermediate hosts to many cercariae simultaneously induces higher mortalities than the gradual exposure to low numbers typical of field conditions (e.g. Fredensborg et al., 2004b). Also, several consecutive days of unseasonably hot weather and the associated increase in cercarial production by trematodes on intertidal mudflats can cause the mass mortality and local extinction of the parasites' second intermediate hosts (Jensen \& Mouritsen, 1992). Thus, there is no need for the increased cercarial output to be maintained over many weeks or months, for the temperature-mediated effects of parasites to have a substantial ecological impact.

Secondly, an increase in the quantity of cercariae being produced may not lead to increased transmission if the cercariae are of lower quality. Cercarial quality is the product of their survivorship and their infectivity or transmission success to the next host. Generally, cercarial survival decreases steadily with increasing temperature (e.g. Evans, 1985; McCarthy, 1999; Mouritsen, 2002b). This follows directly from the greater activity of cercariae at higher temperatures and the faster depletion of their finite energy reserves (Pechenik \& Fried, 1995; McCarthy, 1999). In contrast, cercarial infectivity, measured as the likelihood that a cercaria will successfully infect its target host under standard conditions, generally increases with temperature before dropping off at high temperatures (e.g. Evans, 1985; McCarthy, 1999). Combining cercarial survival and cercarial infectivity into a single measure of transmission efficiency shows that cercarial transmission is not negatively affected by increasing temperatures (Evans, 1985; McCarthy, 1999). Low cercarial infectivity at lower temperatures is offset by low mortality, while improved infectivity at higher temperatures is counterbalanced by high mortality. Thus, in the trematode species investigated to date, transmission efficiency remains roughly constant between approximately $15^{\circ}$ and $30^{\circ} \mathrm{C}$ (Evans, 1985; McCarthy, 1999). Under these conditions, a temperature-mediated increase in cercarial output could therefore lead to greater infection levels in the next hosts of trematodes. The fact that the general activity of these ectothermic invertebrate hosts will also increase as a function of temperature, in turn increasing the likelihood of contact between host and parasite (see e.g. Mouritsen \& Jensen, 1997; Mouritsen et al., 2003), only serves to reinforce the process. Given the ubiquitous presence and ecological importance of trematodes in intertidal systems (see above; Sousa, 1991; Mouritsen \& Poulin, 2002b), global warming is therefore likely to induce community-wide changes mediated by increased trematode parasitism.

\section{Predicting the impact of global warming}

Could temperature-mediated increases in parasitism cause the local extinction of host species, or other major impacts on intertidal communities? Answering such questions for any given host-parasite association is almost impossible. It would require quantitative information not just on how an increase in temperature will affect the production of parasite infective stages, but also on how it would affect all other aspects of host and parasite population biology. This information is lacking, and without it one cannot build realistic models forecasting the effects of global warming. There is, however, one very well-studied host-parasite association, between an intertidal amphipod and its trematode parasites, for which sufficient information is available.

On intertidal mudflats in the Danish Wadden Sea, as well as in other localities along the coast of northern Europe, two of the most abundant macroinvertebrates are the snail Hydrobia ulvae and the amphipod Corophium volutator. These are, respectively, the first and second intermediate hosts of two closely-related trematodes, Maritrema subdolum and Microphallus claviformis (Microphallidae); shorebirds, mainly dunlins Calidris alpina, are the definitive hosts. The two parasite species have identical life cycles and are essentially playing equivalent roles in this system. Adult worms release their eggs in the birds' faeces, as the latter are deposited on the mudflat surface. After parasite eggs are accidentally ingested by grazing snails, they develop within the snail and multiply asexually into cercariae. The latter then leave the snail to penetrate and encyst in amphipods. The life cycle is completed when an amphipod, and the metacercariae it harbours, are ingested by a bird. Infected snails are ultimately castrated by the parasites and suffer from higher mortality when exposed to environmental stress (Jensen \& Mouritsen, 1992; Mouritsen \& Jensen, 1994; Jensen et al., 1996). Similarly, the trematodes increase the mortality rates of the amphipod C. volutator under both laboratory (Mouritsen \& Jensen, 1997; Jensen et al., 1998; Meissner \& Bick, 1999) and field conditions (Jensen \& Mouritsen, 1992; Meissner \& Bick, 1997).

Significant effects of ambient temperature on all key processes, such as parasite transmission efficiency, cercarial production rates, or parasite-induced mortality in both snails and amphipods, have been documented in this system (Mouritsen \& Jensen, 1997; Mouritsen et al., 1998). A recent simulation model has been constructed to encapsulate the network of direct and indirect effects of ambient temperature in this system, and integrate them in a predictive framework (Mouritsen et al., 2005). The model has been used to answer the following basic question: what would be the overall effect of a small increase in temperature on the populations of amphipod hosts? Using mean monthly temperatures recorded over the last few years, the model predicts essentially the same annual fluctuation in amphipod density as that recorded in field surveys (Mouritsen et al., 2005), with a late summer peak close to 100,000 amphipods $\mathrm{m}^{-2}$. It thus 
captures the fundamental dynamics of the amphipod population. By increasing temperatures gradually in the model, by $0.5^{\circ} \mathrm{C}$ increments, one can predict what would happen to the amphipod population in the event of global warming (fig. 2). The minimum annual population density of amphipods decreases with increasing temperature, reaching zero before a $4^{\circ} \mathrm{C}$ temperature increase (fig. 2). In other words, the model predicts that amphipod populations will experience regular local extinctions if the air and sea surface temperatures rise by just a few degrees (Mouritsen et al., 2005). From the model, it is easy to demonstrate that the factor responsible for this result is parasite-induced mortality: the greater output of cercariae from snails at the higher temperatures leads to more severe infection of amphipods, and thus to elevated amphipod mortality. Even by tweaking the model to try to give the amphipods a chance (e.g. by allowing them a longer reproductive season), the outcome is the same: extinction when the temperature increase reaches about $4^{\circ} \mathrm{C}$ (Mouritsen et al., 2005). The Danish Meteorological Institute predicts increases in near-ground air temperature of up to $6^{\circ} \mathrm{C}$ in the Wadden Sea area over the next 70 years (Christensen et al., 1998, 2001). Putting these predictions together, we can forecast frequent extinctions of amphipod populations along the Danish coast in the coming decades. A recent study adds support to this forecast. In parts of the Dutch Wadden Sea, populations of the amphipod $C$. volutator have been declining since the early 1970 s (Beukema \& Dekker, 2005), a period during which climate changes have resulted in steadily milder winters. Although both the decline in amphipod populations and the winter warming have been subject to stochastic fluctuations, the overall pattern is consistent with temperaturemediated effects of parasitism on amphipods.

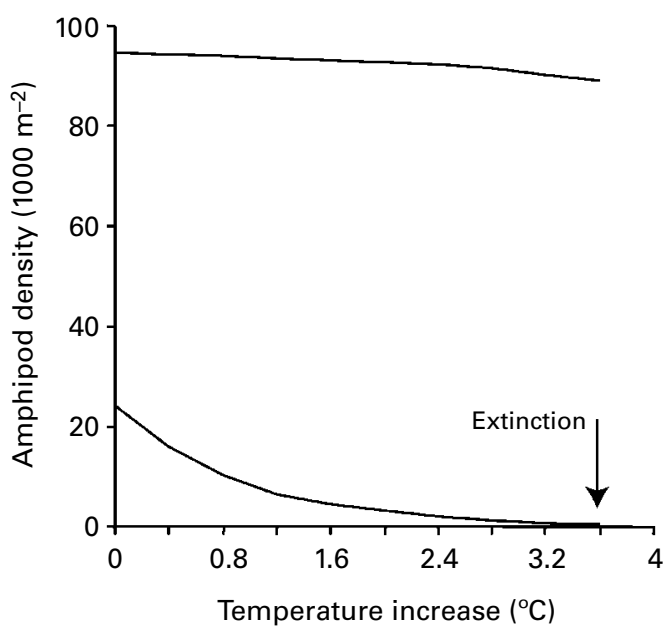

Fig. 2. Simulation of the effect of climate warming on the density of amphipod (Corophium volutator) populations in the Wadden Sea. Minimum (bottom line) and maximum (top line) annual amphipod population densities, given trematode-induced amphipod mortality, in relation to an increase in mean temperature. When the minimum density reaches zero, the population goes extinct (from Mouritsen et al., 2005)
Do the frequent local extinctions of a small amphipod like Corophium volutator matter to the broader intertidal system? The answer is yes. The impact of parasiteinduced host extinctions following a rise in temperature will surely extend beyond the populations of amphipods, given the role played by the latter on intertidal mudflats. An incident that occurred several years ago illustrates this clearly. After unseasonably high temperatures and a massive die-off of amphipods, driven by unusually high levels of trematode infections, the disappearance of the tube-building amphipods lead to drastic changes in erosion patterns, sediment characteristics, and microtopography of mudflats in parts of the Danish Wadden Sea (Jensen \& Mouritsen, 1992; Mouritsen et al., 1998; Mouritsen \& Poulin, 2002b). The stabilizing influence of the amphipods' tubes contributes significantly to the physical nature of the mudflats. Their disappearance was accompanied by significant changes in the abundance of other macrofaunal species on the mudflats (Jensen \& Mouritsen, 1992). Parasitism by trematodes in C. volutator can thus have community-wide impacts, and the increased local extinctions of this amphipod that are likely to result from global warming will have wide repercussions.

\section{Conclusions}

Parasites are very common in all major taxa found in intertidal soft-sediment habitats. Using examples of parasites capable of regulating host population densities or of influencing the composition of entire communities, we have argued that parasites are major players in the intertidal ecosystems. Their modest total biomass does not do justice to their potential ecological impact. Furthermore, several physiological and ecological processes inherent to parasite transmission or pathology are likely to be altered by climate changes. In particular, global warming will almost certainly result in enhanced proliferation of trematode infective stages, not just in intertidal ecosystems but also in terrestrial and freshwater habitats as well. We argue that increased levels of parasitic infections will have substantial repercussions for intertidal communities, as illustrated by the results of a simulation model that predicts frequent local parasiteinduced extinctions of a mudflat amphipod following a modest increase in ambient temperatures. Of course, such predictions rest to some extent on the assumption that there would be no other major environmental modification caused by climate change. Still, within the realistic framework of the model, host extinction is the consistent outcome of a range of simulations based on slightly different scenarios, suggesting that it is not a question of if and how extinctions will occur, but when.

On the bright side, the extreme sensitivity of trematodes to temperature increases can provide us with a new tool to monitor the ecological impact of climate change. Parasites have been considered before as potential indicators of environmental change, such as pollution and other anthropogenic habitat degradation (see Lafferty, 1997); they can serve a similar function in the context of climate change. The marked increase in cercarial release shown by apparently all trematodes 
should be relatively easy to record as a greater average load of metacercariae in second intermediate hosts. This should be relatively easy to monitor over time in a range of systems, providing an early warning signal that global warming is affecting intertidal communities. It would be nice to think that governments and industries would join forces and work to prevent or slow down global climate change. While we wait for that to happen, it would be wise to include parasites and their effects in any assessment of the potential impact of climate change on natural ecosystems, and to consider using parasites as sensitive tools for monitoring this impact.

\section{Acknowledgements}

This paper was presented at the Black Forest Symposium entitled "Environmental and ecological parasitology: the impact of global change" held in Freudenstadt, Germany, Spring 2005. RP is grateful to B. Sures and H. Taraschewski for the invitation to participate in the Black Forest Symposium. The work described here was partially supported by a grant from the Marsden Fund of New Zealand to RP, and by a grant from the Carlsberg Foundation to KNM.

\section{References}

Albon, S.D., Stien, A., Irvine, R.J., Langvatn, R., Ropstad, E. \& Halvorsen, O. (2002) The role of parasites in the dynamics of a reindeer population. Proceedings of the Royal Society of London B 269, 1625-1632.

Babirat, C., Mouritsen, K.N. \& Poulin, R. (2004) Equal partnership: two trematode species, not one, manipulate the burrowing behaviour of the New Zealand cockle, Austrovenus stutchburyi. Journal of Helminthology 78, 195-199.

Beukema, J.J. \& Dekker, R. (2005) Decline of recruitment success in cockles and other bivalves in the Wadden Sea: possible role of climate change, predation on postlarvae and fisheries. Marine Ecology Progress Series 287, 149-167.

Cattadori, I.M., Haydon, D.T. \& Hudson, P.J. (2005) Parasites and climate synchronize red grouse populations. Nature 433, 737-741.

Christensen, O.B., Christensen, J.H., Machenhauer, B. \& Botzet, M. (1998) Very high-resolution regional climate simulations over Scandinavia - present climate. Journal of Climate 11, 3204-3229.

Christensen, J.H., Raisanen, J., Iversen, T., Bjorge, D., Christensen, O.B. \& Rummukainen, M. (2001) A synthesis of regional climate change simulations - a Scandinavian perspective. Geophysical Research Letters 28, 1003-1006.

Combes, C. (1996) Parasites, biodiversity and ecosystem stability. Biodiversity and Conservation 5, 953-962.

Donald, K.M., Kennedy, M., Poulin, R. \& Spencer, H.G. (2004) Host specificity and molecular phylogeny of larval Digenea isolated from New Zealand and Australian topshells (Gastropoda: Trochidae). International Journal for Parasitology 34, 557-568.
Evans, N.A. (1985) The influence of environmental temperature upon transmission of the cercariae of Echinostoma liei (Digenea: Echinostomatidae). Parasitology 90, 269-275.

Fredensborg, B.L., Latham, A.D.M. \& Poulin, R. (2004a) New records of gastrointestinal helminths from the red-billed gull (Larus novaehollandiae scopulinus). New Zealand Journal of Zoology 31, 75-80.

Fredensborg, B.L., Mouritsen, K.N. \& Poulin, R. (2004b) Intensity-dependent mortality of Paracalliope novizealandiae (Amphipoda: Crustacea) infected by a trematode: experimental infections and field observations. Journal of Experimental Marine Biology and Ecology 311, 253-265.

Fredensborg, B.L., Mouritsen, K.N. \& Poulin, R. (2005) Impact of trematodes on host survival and population density in the intertidal gastropod Zeacumantus subcarinatus. Marine Ecology Progress Series 290, $109-117$.

Harvell, C.D., Kim, K., Burkholder, J.M., Colwell, R.R., Epstein, P.R., Grimes, D.J., Hofmann, E.E., Lipp, E.K., Osterhaus, A.D.M.E., Overstreet, R.M., Porter, J.W., Smith, G.W. \& Vasta, G.R. (1999) Emerging marine diseases: climate links and anthropogenic factors. Science 285, 1505-1510.

Harvell, C.D., Mitchell, C.E., Ward, J.R., Altizer, S., Dobson, A.P., Ostfeld, R.S. \& Samuel, M.D. (2002) Climate warming and disease risks for terrestrial and marine biota. Science 296, 2158-2162.

Holmgren, M., Scheffer, M., Ezcurra, E., Gutierrez, J.R. \& Mohren, G.M.J. (2001) El Niño effects on the dynamics of terrestrial ecosystems. Trends in Ecology and Evolution 16, 89-94.

Hudson, P.J., Dobson, A.P. \& Newborn, D. (1998) Prevention of population cycles by parasite removal. Science 282, 2256-2258.

Huxham, M., Raffaelli, D. \& Pike, A. (1995) Parasites and food web patterns. Journal of Animal Ecology 64, $168-176$

Jensen, K.T., Latama, G. \& Mouritsen, K.N. (1996) The effect of larval trematodes on the survival rates of two species of mud snails (Hydrobiidae) experimentally exposed to desiccation, freezing and anoxia. Helgoländer Meeresuntersuchungen 50, 327-335.

Jensen, K.T. \& Mouritsen, K.N. (1992) Mass mortality in two common soft-bottom invertebrates, Hydrobia ulvae and Corophium volutator: the possible role of trematodes. Helgoländer Meeresuntersuchungen 46, 329-339.

Jensen, T., Jensen, K.T. \& Mouritsen, K.N. (1998) The influence of the trematode Microphallus claviformis on two congeneric intermediate host species (Corophium): infection characteristics and host survival. Journal of Experimental Marine Biology and Ecology 227, 35-48.

Lafferty, K.D. (1997) Environmental parasitology: what can parasites tell us about human impacts on the environment? Parasitology Today 13, 251-255.

Lafferty, K.D., Porter, J.W. \& Ford, S.E. (2004) Are diseases increasing in the ocean? Annual Review of Ecology, Evolution and Systematics 35, 31-54.

Latham, A.D.M. \& Poulin, R. (2002a) New records of gastrointestinal helminths from the southern blackbacked gull (Larus dominicanus) in New Zealand. New Zealand Journal of Zoology 29, 253-257. 
Latham, A.D.M. \& Poulin, R. (2002b) Field evidence of the impact of two acanthocephalan parasites on the mortality of three species of New Zealand shore crabs (Brachyura). Marine Biology 141, 1131-1139.

Lauckner, G. (1987) Ecological effects of larval trematode infestations on littoral marine invertebrate populations. International Journal for Parasitology 17, 391-398.

Lo, C.-T. \& Lee, K.-M. (1996) Pattern of emergence and the effects of temperature and light on the emergence and survival of heterophyid cercariae (Centrocestus formosanus and Haplorchis pumilio). Journal of Parasitology 82, 347-350.

Marcogliese, D.J. (2001) Implications of climate change for parasitism of animals in the aquatic environment. Canadian Journal of Zoology 79, 1331-1352.

McCarthy, A.M. (1999) The influence of temperature on the survival and infectivity of the cercariae of Echinoparyphium recurvatum (Digenea: Echinostomatidae). Parasitology 118, 383-388.

Meissner, K. \& Bick, A. (1997) Population dynamics and ecoparasitological surveys of Corophium volutator in coastal waters in the Bay of Mecklenburg (southern Baltic Sea). Diseases of Aquatic Organisms 29, 169-179.

Meissner, K. \& Bick, A. (1999) Mortality of Corophium volutator (Amphipoda) caused by infestation with Maritrema subdolum (Digenea, Microphallidae): laboratory studies. Diseases of Aquatic Organisms 35, 47-52.

Minchella, D.J. \& Scott, M.E. (1991) Parasitism: a cryptic determinant of animal community structure. Trends in Ecology and Evolution 6, 250-254.

Moravec, F., Fredensborg, B.L., Latham, A.D.M. \& Poulin, R. (2003) Larval Spirurida (Nematoda) from the crab Macrophthalmus hirtipes in New Zealand. Folia Parasitologica 50, 109-114.

Mouritsen, K.N. (2002a) The parasite-induced surfacing behaviour in the cockle Austrovenus stutchburyi: a test of an alternative hypothesis and identification of potential mechanisms. Parasitology 124, 521-528.

Mouritsen, K.N. (2002b) The Hydrobia ulvae-Maritrema subdolum association: influence of temperature, salinity, light, water-pressure and secondary host exudates on cercarial emergence and longevity. Journal of Helminthology 76, 341-347.

Mouritsen, K.N. \& Jensen, K.T. (1994) The enigma of gigantism: effect of larval trematodes on growth, fecundity, egestion and locomotion in Hydrobia ulvae (Pennant) (Gastropoda: Prosobranchia). Journal of Experimental Marine Biology and Ecology 181, 53-66.

Mouritsen, K.N. \& Jensen, K.T. (1997) Parasite transmission between soft-bottom invertebrates: temperature mediated infection rates and mortality in Corophium volutator. Marine Ecology Progress Series 151, 123-134

Mouritsen, K.N. \& Poulin, R. (2002a) Parasitism, climate oscillations and the structure of natural communities. Oikos 97, 462-468.

Mouritsen, K.N. \& Poulin, R. (2002b) Parasitism, community structure and biodiversity in intertidal ecosystems. Parasitology 124, S101-S117.
Mouritsen, K.N. \& Poulin, R. (2005a) Parasites boost biodiversity and change animal community structure by trait-mediated indirect effects. Oikos 108, 344-350.

Mouritsen, K.N. \& Poulin, R. (2005b) Parasitism can influence the intertidal zonation of non-host organisms. Marine Biology 148, 1-11.

Mouritsen, K.N., Mouritsen, L.T. \& Jensen, K.T. (1998) Changes of topography and sediment characteristics on an intertidal mud-flat following mass-mortality of the amphipod Corophium volutator. Journal of the Marine Biological Association of the UK 78, 1167-1180.

Mouritsen, K.N., McKechnie, S., Meenken, E., Toynbee, J.L. \& Poulin, R. (2003) Spatial heterogeneity in parasite loads in the New Zealand cockle: the importance of host condition and density. Journal of the Marine Biological Association of the UK 83, 307-310.

Mouritsen, K.N., Tompkins, D.M. \& Poulin, R. (2005) Climate warming may cause a parasite-induced collapse in coastal amphipod populations. Oecologia 146, 476-483.

Mysterud, A., Stenseth, N.C., Yoccoz, N.G., Langvatn, R. \& Steinheim, G. (2001) Nonlinear effects of large-scale climatic variability on wild and domestic herbivores. Nature 410, 1096-1099.

Ottersen, G., Planque, B., Belgrano, A., Post, E., Reid, P.C. \& Stenseth, N.C. (2001) Ecological effects of the North Atlantic Oscillation. Oecologia 128, 1-14.

Patz, J.A., Graczyk, T.K., Geller, N. \& Vittor, A.Y. (2000) Effect of environmental change on emerging parasitic diseases. International Journal for Parasitology 30, 1395-1405.

Pearson, E.J. \& Cheng, T.C. (1985) Studies on parasitic castration: occurrence of a gametogenesis-inhibiting factor in extract of Zoogonus lasius (Trematoda). Journal of Invertebrate Pathology 46, 239-246.

Pechenik, J.A. \& Fried, B. (1995) Effect of temperature on survival and infectivity of Echinostoma trivolvis cercariae: a test of the energy limitation hypothesis. Parasitology 111, 373-378.

Pechenik, J.A., Fried, B. \& Simpkins, H.L. (2001) Crepidula fornicata is not a first intermediate host for trematodes: who is? Journal of Experimental Marine Biology and Ecology 261, 211-224.

Phoenix, G.K. \& Lee, J.A. (2004) Predicting impacts of Arctic climate change: past lessons and future challenges. Ecological Research 19, 65-74.

Poulin, R. (2006) Global warming and temperaturemediated increases in cercarial emergence in trematode parasites. Parasitology 132, 143-151.

Poulin, R. \& Mouritsen, K.N. (2003) Large-scale determinants of trematode infections in intertidal gastropods. Marine Ecology Progress Series 254, 187-198.

Poulin, R., Nichol, K. \& Latham, A.D.M. (2003) Host sharing and host manipulation by larval helminths in shore crabs: cooperation or conflict? International Journal for Parasitology 33, 425-433.

Poulin, R., Steeper, M.J. \& Miller, A.A. (2000) Nonrandom patterns of host use by the different parasite species exploiting a cockle population. Parasitology 121, 289-295. 
Schmidt-Nielsen, K. (1997) Animal physiology: adaptation and environment. 5th edn. Cambridge, Cambridge University Press.

Scott, M.E. (1987) Regulation of mouse colony abundance by Heligmosomoides polygyrus. Parasitology 95, 111-124.

Sousa, W.P. (1983) Host life history and the effect of parasitic castration on growth: a field study of Cerithidea californica Haldemann (Gastropoda: Prosobranchia) and its trematode parasites. Journal of Experimental Marine Biology and Ecology 73, 273-296.

Sousa, W.P. (1991) Can models of soft-sediment community structure be complete without parasites? American Zoologist 31, 821-830.

Stenseth, N.C., Mysterud, A., Ottersen, G., Hurrell, J.W., Chan, K.-S. \& Lima, M. (2002) Ecological effects of climate fluctuations. Science 297, 1292-1296.

Stenseth, N.C., Ottersen, G., Hurrell, J.W., Mysterud, A., Lima, M., Chan, K.-S., Yoccoz, N.G. \& Adlandsvik, B. (2003) Studying climate effects on ecology through the use of climate indices: the North Atlantic Oscillation, El Niño Southern Oscillation and beyond. Proceedings of the Royal Society of London B 270, 2087-2096.

Thomas, F. \& Poulin, R. (1998) Manipulation of a mollusc by a trophically transmitted parasite: convergent evolution or phylogenetic inheritance? Parasitology 116, 431-436.

Thomas, F., Renaud, F., de Meeûs, T. \& Poulin, R. (1998) Manipulation of host behaviour by parasites: ecosystem engineering in the intertidal zone? Proceedings of the Royal Society of London B 265, 1091-1096.

Thomas, F., Renaud, F. \& Guégan, J.-F. (2005) Parasitism and ecosystems. Oxford, Oxford University Press.

Thompson, R.M., Mouritsen, K.N. \& Poulin, R. (2005) Importance of parasites and their life cycle characteristics in determining the structure of a large marine food web. Journal of Animal Ecology 74, 77-85.

Umadevi, K. \& Madhavi, R. (1997) Effects of light and temperature on the emergence of Haplorchis pumilio cercariae from the snail host, Thiara tuberculata. Acta Parasitologica 42, 12-16.

Vaughan, D.G., Marshall, G.J., Connolley, W.M., Parkinson, C., Mulvaney, R., Hodgson, D.A., King, J.C., Pudsey, C.J. \& Turner, J. (2003) Recent rapid regional climate warming on the Antarctic Peninsula. Climatic Change 60, 243-274.

Walther, G.-R., Post, E., Convey, P., Menzel, A., Parmesan, C., Beebee, T.J.C., Fromentin, J.-M., Hoegh-Guldberg, O. \& Bairlein, F. (2002) Ecological responses to recent climate change. Nature 416, 389-395.

Willmer, P., Stone, G. \& Johnston, I. (2000) Environmental physiology of animals. Oxford, Blackwell Science.

(Accepted 15 November 2005) (C) CAB International, 2006 